\title{
ELEMENTOS PARA CRÍTICA À TESE DE INVENÇÃO DO NORDESTE
}

\section{ELEMENTS TO CRITICIZE THE NORTHEAST INVENTION THESIS}

\author{
Nivalter Aires dos Santos ${ }^{1}$ \\ 1 Universidade Federal do Rio Grande do Norte, Doutorando do Programa de Pós-graduação em \\ Ciências Sociais, Brasil, e-mail: aires.nivalter@gmail.com
}

\author{
ARTICLE INFO \\ Article history: \\ Received 2019-07-02 \\ Accepted 2019-09-06 \\ Available online 2019-09-06
}

\begin{abstract}
Palavras-chave: Pensamento Político Brasileiro. Questão Nordestina. Invenção do Nordeste. Movimento Regionalista. Geração de 30.

Keywords: Brazilian Political Thinking. Northeast Question. Northeast Invention. Regionalist Movement. Generation of Thirty.
\end{abstract}

RESUMO. Desde a década de 1990 tem ganhado destaque a tese de que o Nordeste é uma invenção - uma produção imagético-discursiva - essa leitura foi elaborada pelo historiador Durval Muniz e está apresentada no seu livro "A Invenção do Nordeste e outras artes". Ele parte de uma construção historiográfica foucaultiana e propõe que, a partir do discurso, alguns movimentos político-culturais criaram a região Nordeste. Diante disso, nosso objetivo é produzir uma crítica radical a esta tese. Nos amparamos teórico-metodologicamente numa leitura materialista e dialética da história, propondo a "crítica" como método de apreensão do conhecimento de caráter político e social. Para isso consultamos amplo acervo bibliográfico, contemplando além da leitura detalhada do trabalho do Durval Muniz, os interlocutores dele, a saber: Gilberto Freyre e os romancistas da geração de 30. Como resultados, indicamos que há um conjunto de fragilidades na leitura de Durval Muniz, que tendem a homogeneização do espaço regional, desconsideração de leituras importantes sobre o Nordeste, especialmente no que se refere ao tema do desenvolvimento.

\begin{abstract}
Since the 1990s, the thesis that the Northeast is an invention - an imagery-discursive production - has gained prominence. This theory was elaborated by the historian Durval Muniz and is presented in his book "A Invenção do Nordeste e outras artes". From a Foucaultian historiographical construction, he proposes that some political-cultural movements created the Northeast region. Therefore, our objective is to produce a radical critique of this thesis. We use the theoreticalmethodological approach of materialism and the dialectic in historical analysis, proposing "criticism" as a method of apprehending knowledge of a political and social nature. For this we consulted a large bibliographical collection, contemplating, besides Durval Muniz, his interlocutors, namely: Gilberto Freyre and the novelists of the generation of 30 . As results we present that there are weaknesses in the analysis of Durval Muniz, which tend to the homogenization of the regional space; and disregards important approaches to the Northeast Question, especially on the issue of development.
\end{abstract}

\section{Introdução}

O Brasil, enquanto um país de dimensões continentais, abriga uma profunda questão regional que no nível da aparência (aquilo que está às vistas) se apresenta através da pobreza da região Nordeste em contraste com a riqueza do Centro-sul. Com a finalidade de explicar este fenômeno muito se escreveu e se propôs desde princípios do século XX, e, dessa forma, a "pobreza" nordestina tem sido atribuída a diversas causas. 
Uma proposição de explicação de Nordeste e da Questão Nordestina foi formulado pelo historiador Durval Muniz de Albuquerque Jr., na sua tese de doutoramento defendida na Universidade Estadual de Campinas (UNICAMP) em 1994, ganhando logo em seguida publicação no formato de livro: A invenção do Nordeste e outras artes. Esta proposta de que o Nordeste brasileiro seria uma invenção, uma produção imagético-discursiva, tem gozando de grande aceitação desde sua publicação.

Em virtude da popularidade e pelo fato de seguir angariando adeptos, acreditamos que vale a pena dignar-se a elaborar uma crítica aos limites dessa abordagem. $\mathrm{O}$ autor apresenta uma leitura pós-moderna do espaço regional associado à valorização da identidade e representação, ou mais precisamente do discurso, obtendo como resultado o entendimento de que a região Nordeste seria um espaço simbólico.

A historiadora Margareth Rago (1995) destaca que o trabalho de Durval Muniz (2011) se insere numa nova trilha de trabalhos historiográficos que utilizam Michel Foucault como referencial metodológico num esforço de pensar diferentemente a história. Nesse sentido, Durval Muniz apresenta que alguns movimentos político-culturais - Movimento Regionalista, Geração de 30 , bem como outros - ou mais precisamente os discursos elaborados pelos intelectuais/artistas envolvidos nestes criaram o Nordeste enquanto região. Propondo, desse modo, que o Nordeste é uma produção imagético-discursiva, uma invenção.

Objetivamos, neste trabalho, produzir uma crítica radical (pela raiz) a esta tese de invenção do Nordeste, não uma crítica pela crítica, longe disso, mas uma crítica no sentido dialético. Para isso propomos uma revisão bibliográfica que contempla, além da leitura detalhada do trabalho do Durval Muniz, os interlocutores dele, a saber Gilberto Freyre e os romancistas da geração de 30, particularmente Graciliano Ramos.

Destacamos metodologicamente a "crítica" como método de apreensão do conhecimento de caráter político e social. Luciana Aliaga (2017, p. 31) analisando ciência e arte política nos Cadernos do Cárcere de Antonio Gramsci, enfatiza que para este intelectual o elemento que deve estar necessariamente presente na construção científica independente da sua especialidade é, justamente, a crítica.

Sobre esse aspecto, Antonio Gramsci, no $\S 15$ do caderno 11, indica que ao se fazer a crítica não se deve "escolher os adversários entre os mais estúpidos e medíocres, ou, ainda, escolher entre as opiniões dos próprios adversários as menos essenciais e as mais ocasionais" (GRAMSCI, 2015, p. 123). Além disso, deve-se ser justo com eles, de modo que "é necessário esforçar-se para compreender o que ele realmente quer dizer, e não fixar-se maliciosamente nos significados superficiais e imediatos de suas expressões" (GRAMSCI, 2015, p. 123-124).

Com isto o que está proposto é a elevação do debate para um patamar superior. Desse modo, estamos amparados teórico-metodologicamente numa leitura materialista e dialética, 
levando em consideração o movimento e a contradição dos processos econômicos político e sociais.

Karl Marx (2016a, p. 72) entende que a ciência histórica e social deve observar o desenvolvimento das categorias econômicas na realidade (concreto) e na mente (abstrato), de modo que essas categorias possam expressar formas e modos de existência. Afinal, são as formas de produção que criam as relações jurídicas, ou seja, não se pode explicar uma época de transformações a partir da sua consciência ou ideologia, mas sim explicar essa consciência (ou conjunto de ideologias) a partir das contradições da vida material, do conflito existente entre forças produtivas e relações de produção sociais. Complementando "não é a consciência dos homens que determina o seu ser, mas, inversamente, o seu ser social que determina a sua consciência" (MARX, 2016b, p. 39).

No cerne da teoria marxista da criação ideológica - estudos sobre o conhecimento científico, a literatura, a religião, a moral, etc. - percebe-se que os produtos ideológicos fazem parte de uma realidade natural ou social como um signo que possui um significado que remete a algo fora de si. Esses signos ideológicos não são apenas um reflexo da realidade social, mas sim um fragmento dessa realidade. A consciência, como aparece nos textos de Marx, torna-se consciência somente quando se impregna de conteúdo ideológico e, consequentemente, somente no processo de interação social (BAKHTIN, 2014, p. 31-34).

Estabelece-se uma relação entre discurso e signo a partir de um espaço de disputa ideológica, com marcante presença da perspectiva hegemônica das classes dominantes intimamente relacionada à manutenção do status quo. Como apontou Marx e Engels, n'A Ideologia Alemã:

As ideias da classe dominante são, em cada época, as ideias dominantes, isto é, a classe que é a força material dominante da sociedade é, ao mesmo tempo, sua força espiritual dominante [...] As ideias dominantes não são nada mais do que a expressão ideal a das relações materiais dominantes, são as relações materiais dominantes apreendidas como ideias; portanto, são a expressão das relações que fazem de uma classe a classe dominante, são as ideias de sua dominação (MARX; ENGELS, 2007, p. 47).

Diante disso, toma-se como instrumento de pesquisa a leitura crítica dos principais argumentos elaborados em defesa da tese de "invenção do nordeste" de Durval Muniz, trazendo para o debate leituras diversas de interlocutores dele, e outros que se debruçaram no amplo debate sobre o Nordeste brasileiro.

\section{Sobre o discurso de que o Nordeste foi inventado}

A proposição de "invenção do nordeste" a partir da uma construção historiográfica foucaultiana diz que movimentos políticos e culturais criaram a região Nordeste, apontando para a ideia que as práticas racionalizantes se cruzaram com uma série de discursos políticos e culturais que sedimentaram uma ideia de Nordeste. 
Elemento central nesse processo, para Durval Muniz (2011), foi o regionalismo freyreano que não seria uma justificativa ideológica de um lugar social ameaçado, mas sim uma nova forma de ver, conhecer e dizer a realidade. Também o movimento literário de trinta - segunda geração modernista - que teria se apoiado pelo discurso regional.

Seguindo essa perspectiva o Nordeste seria o filho reacionário da modernidade, uma maquinaria imagético-discursiva gestada para conter o processo de desterritorialização pelo qual estaria passando os grupos sociais desta área, provocada pela subordinação a outra área do país que se modernizava rapidamente, claramente o Centro-sul. Diante disso o autor, como ele propõe, não intencionava em sua obra defender o Nordeste, muito pelo contrário, queria atacá-lo, queria a dissolução dessa maquinaria imagético-discursiva de reprodução das relações econômico-sociais e de poder (ALBUQUERQUE JR., 2011, 342).

O Congresso Regionalista de 1926 teria sido o primeiro trabalho para legitimar o recorte Nordeste. Gilberto Freyre, em sua posição de intelectual teve enorme destaque nesse processo, através da busca das "verdadeiras raízes regionais", através da manutenção da tradição, e a consequente garantia da perpetuação de privilégios e lugares sociais ameaçados (ALBUQUERQUE JR., 2011, p. 88-90). As ideias do movimento estão sintetizadas no Manifesto Regionalista redigido por Gilberto Freyre (1996) e, supostamente, apresentado no Primeiro Congresso Brasileiro de Regionalismo que aconteceu na cidade do Recife (PE), durante o mês de fevereiro de 1926.

Em relação a data de publicação do manifesto há uma certa polêmica, seu conteúdo poderia facilmente ter sido produzido na década de 1920, mas há quem diga que o ele simplesmente inexistiu e só foi produzido na década de 1950. Ao menos isso é o que foi apresentado por Wilson Martins e Joaquim Inojosa, rivais de Freyre, na década de 1960, quando em pesquisa documental não encontraram alusão a tal texto em nenhum dos jornais da época em que o Congresso aconteceu (DANTAS, 2015).

Entendemos que o movimento regionalista, que tinha em Freyre sua principal referência é um contra-movimento que incorporou de forma moderada alguns elementos do modernismo por um lado, e se apegou às tradições regionais, por outro (ANDRADE, 2013). Ao contrário do que representou o movimento modernista de 1922, o movimento regionalista propunha o resgate das raízes nacionais na busca pela preservação e fortalecimento das tradições do Nordeste resgatando a cultura regional do espaço que tinha sido o centro econômico e cultural do país.

Dialeticamente se pode analisar Freyre como um intelectual tradicional ligado à aristocracia açucareira que em sua escrita deixa claro seus temores diante das transformações na ordem social, e assim busca, na defesa da região, espaço político para as classes tradicionais nordestinas que perdiam cada vez mais espaço no cenário nacional mais amplo. Não se trata de uma simplificação do complexo pensamento de Freyre que envolve 
uma produção sociológica de décadas sobre aspectos diversos relacionados à cultura, mas de tentar demarcar no que se refere a questão nordestina as posições assumidas por este intelectual.

No livro Nordeste de Gilberto Freyre (2013) não apresenta um Nordeste único e indivisível, ele abre espaço para que se reconheça a existência dos outros "vários Nordestes", dentro da diversidade que compõe esta região, ele se propõe a apresentar o Nordeste açucareiro das terras férteis de massapê, da cana-de-açúcar, dos grandes senhores de engenho montados em seus vultosos cavalos é marcado pela abundância da água.

Freyre (2013) apresenta a fisionomia do Nordeste agrário do açúcar, que estava em decadência, particularmente na década de 1930, mas que foi o centro da civilização brasileira no primeiro período colonial. Esse Nordeste tinha como características a monocultura, a escravidão, o latifúndio, como marcas características da paisagem. À Freyre interessa as férteis terras de massapé que representou para o Brasil o estabelecimento da civilização moderna mais sedentária que o português fundou nos trópicos: a do açúcar no Nordeste do Brasil.

O Nordeste, em Durval Muniz, seria o espaço da reação ao processo de modernização, "uma rugosidade do espaço nacional, que surge a partir de uma aliança de forças, que busca barrar o processo de integração nacional, feita a partir do Centro-Sul" (ALBUQUERQUE JR., 2011, p. 94). Essa leitura homogeniza o Nordeste mais do que o suposto discurso inventor da região, e aponta que o espaço regional se construiu em dupla oposição, primeiro ao processo de modernização e segundo ao processo de integração nacional.

O interessante é perceber que, por mais que mencione aliança de forças, passa ao largo de uma análise mais profunda dos interesses das classes em disputa, por exemplo disputa inter-burguesa entre as frações latifundiária açucareira no litoral nordestino e latifundiária pecuarista no sertão, e estas em oposição a uma fração que se constituía industrial, mas fora latifundiária cafeeira no Centro-sul.

Deve-se considerar que a própria "revolução de 30" que grande expressão desse conflito de interesses e marcou a transição para uma época em que os processos econômicos, políticos, culturais e demográficos se dinamizaram. Nesse contexto a questão nordestina se constitui e aprofundou-se através do processo de integração nacional. Essa integração se afirmou pelas diferenças entre as regiões e o resultado foi um conjunto de problemas de natureza regional, pelo desenvolvimento desigual e combinado do capitalismo obedecendo a ritmos diferenciados nas diferentes regiões.

Entende-se que a "revolução de 30" teve um cunho contra-revolucionário, ela foi feita a partir de cima para evitar que partisse de baixo, a frase proferida pelo presidente da província de Minas Gerais, Antônio Carlos: "façamos a revolução, antes que o povo a faça", é um excelente ilustração. Dessa forma num cenário de crescente inquietação de colonos, 
sitiantes, caboclos e demais... devido a flutuação da cafeicultura e a repercussão na vida das classes e grupos subalternos, a aliança liberal faz sua "revolução burguesa" inaugurando o bloco industrial-agrário (ou bloco desenvolvimentista) que contemplava os interesses da burguesia cafeicultora, indústria, comércio e imperialista (IANNI, 1985, p. 17).

A despeito dessa leitura que fazermos, Durval Muniz segue com outra proposta, apresentando em seu trabalho que:

Quanto mais os golpes de Estado, as ditaduras, as conciliações dos vencedores nos prometem salvar a nação e a região, mais a carência da nação e a carência da região parecem se agravar. Discursos como os da dependência, do subdesenvolvimento como parte do desenvolvimento, da exploração colonial como causas explicativas da nossa situação enquanto país, parecem estar cada vez mais desgastados, porque partem de uma premissa de fundo, que é nossa vitimização enquanto país, a culpa por nosso atraso é dos outros, não nosso, enquanto vencedores e vencidos. O mesmo se pode dizer dos discursos que giram em torno da denúncia do colonialismo interno, das desigualdades regionais, da exploração do Nordeste pelo Sul e vice-versa. São discursos presos a essa lógica da vitimização, da culpa sendo posta sempre no 'outro', criando um 'eu' descomprometido com sua própria condição" (ALBUQUERQUE JR., 2011, p. 346).

Esse parágrafo que aparece na conclusão de sua obra nos fornece diversos aspectos para demarcar a diferença em relação às posições do autor. Primeiro que os golpes de Estado e ditaduras se firmaram sempre contra as classes trabalhadoras e subalternas, no sentido que se constituíram no âmbito de uma contrarrevolução permanente, de modo que coube às frações de classe dominantes, ao fazerem seus acordos pelo alto, excluírem os anseios e demandas populares, deixando de fora do cenário as mudanças que tivessem como horizonte a emancipação.

De modo que enquanto as frações dominantes, mesmo com diferenças pontuais entre si, sempre fizeram os acordos necessários à manutenção da exploração, impedindo a participação das classes trabalhadoras e subalternas pela via de golpes de Estado, manipulação dos partidos, falsificação das eleições, manipulação das estatísticas, formas variadas de violência, etc., como bem destaca Octavio lanni (1985, p. 36-38). Também cabe mencionar as manobras de cooptação, expedientes burocráticos nas organizações de cunho popular como partidos, sindicatos, movimentos sociais, reivindicações e conquistas populares.

Além disso, o que a Durval parece como simples "vitimização" pode ser lido como uma descaracterização de trabalhos com elevado grau de seriedade, sem ao menos adentrar com profundidade nos devidos debates. Por exemplo, faz a crítica ao tema e leitura do subdesenvolvimento, sem trazer Celso Furtado para a discussão (este nem figura como referência bibliográfica no seu livro). Não se trata de cobrar a leitura de todo aquele que escreveu sobre o Nordeste, mas de dar lugar destacado a Celso Furtado que possui uma interpretação que influenciou largamente os estudos sobre o tema através de sua atuação 
política na primeira fase da Superintendência do Desenvolvimento do Nordeste (SUDENE), entre 1959 e 1964.

Critica a noção de dependência, mas não usa como referência ninguém das principais referências sobre a temática, não aparece Florestan Fernandes, Ruy Mauro Marini, nem Fernando Henrique Cardoso, por exemplo. Crítica na mesma medida as interpretações de colonialismo interno e desigualdades regionais sem, tampouco, avançar em argumentos sobre esses temas, nem debatendo com os principais intelectuais que produziram essa análise, que mesmo que discutíveis, merecem o direito a uma crítica consciente e construtiva, no que se refere a análise da questão regional brasileira.

Sobre outro aspecto analisado na Invenção do Nordeste e outras artes, na romantização que fazem alguns intelectuais nordestinos sobre o passado - destacam-se, além de Gilberto Freyre, José Lins do Rego em Menino de Engenho, principalmente - Durval Muniz (2011, p. 100) entende, e tenta convencer, que eles constroem um discurso onde o passado seria melhor do que o presente, e caberia a todos "se baterem pela volta dos antigos territórios esfacelados pela história" na construção do Nordeste, atribuindo ao discurso, enquanto espaço da saudade, a invenção do Nordeste.

Essa análise não está de toda errada, há de fato um saudosismo no movimento regionalista, mas que pouca relação tem com a própria construção do imaginário de Nordeste, e nem mesmo é a visão hegemônica da região, que é muito mais associada ao fenômeno da "seca" do que propriamente a da resplandecente aristocracia açucareira. Seria no mínimo contraditório, ainda que convencido pelo método e proposta de invenção do Nordeste, que esse saudosismo de uma aristocracia açucareira, sedimente o Nordeste "vitimista" das secas, beatos e cangaceiros.

Seguindo essa trilha, sobre o tema da seca, Durval Muniz aponta que:

A seca surge na literatura como aquele fenômeno detonador de transformações radicais da vida das pessoas, desorganizando as famílias social e moralmente. $A$ seca é responsabilizada, inclusive, pelos conflitos sociais na região, pela existência do cangaço e do beato, naturalizando-se as questões sociais (ALBUQUERQUE JR., 2011, p. 139).

Em sua escrita, a seca afeta a vida no âmbito da literatura, a realidade material não aparece. A seca, de fato, tem grande força literária - basta ver A Bagaceira de José Américo de Almeida, O Quinze de Rachel de Queiroz ou Vidas Secas de Graciliano Ramos - mas não só. Não endossamos a ideia de que a seca é a responsável pelos problemas do Nordeste sertanejo, mas negar a importância do fenômeno como detonador, no sentido de ser a falta de chuvas a escancarar a agudeza do problema social, político e econômico dessa sub-região do Nordeste, relegando sua importância ao campo literário (ou do discurso) é demasiado. Os períodos de estiagem de fato desorganizaram a produção agropastoril da forma que era 
montada, e quem mais sofria com o processo eram justamente os despossuídos, aqueles que não dispunham de nada além da sua capacidade de trabalhar.

No âmbito da literatura, a crítica feita por Durval Muniz aos personagens do que ele chama de "as páginas do Nordeste" é de que

são típicos, tipos fixos que mesmo diante de todos os conflitos internos e dos dissabores externos que enfrentam ao longo da trama, nunca chegam a se negar a si mesmos; eles têm garantida a continuidade de 'um modo de ser', de 'um modo de pensar', de 'um modo de agir' regional” (ALBUQUERQUE JR., 2011, p. 126-127).

Trata-se de uma leitura redutora e superficial do universo da segunda geração modernista. Concordamos com a análise feita por Graciliano Ramos, destacada na citação a seguir, sobre a verossimilhança dos personagens que estão enredados em uma complexa realidade social, no texto $O$ romance do Nordeste publicado no Diário de Pernambuco, em março de 1935, onde ele destaca que:

Era indispensável, porém, que nossos romances não fossem escritos no Rio, por pessoas bem-intencionadas, sem dúvida, mas que nos desconheciam inteiramente [...] Em todos os livros do Nordeste, nota-se que os autores tiveram o cuidado de tornar a narrativa, não absolutamente verdadeira, mas verossímil. Ninguém se afasta do ambiente, ninguém confia demasiado na imaginação [...] Esses escritores são políticos, são revolucionários, mas não deram a ideias nomes de pessoas: os seus personagens mexem-se, pensam como nós, sentem como nós, preparam as suas safras de açúcar, bebem cachaça, matam gente e vão para a cadeia, passam fome nos quartos sujos duma hospedaria (RAMOS, 2013, I. 111-112).

Se contrapondo ao otimismo da primeira geração modernista, a segunda (também conhecida como geração de 30) se propôs a apresentar a cruel realidade brasileira. Esses autores e suas obras constituem-se como clássicos da literatura nacional, e lançaram ao país as discussões a partir do lugar e classe da qual se falava.

Esse é o espírito dos romances da geração de 30, eles penetraram profundamente nas contradições de classe da realidade brasileira, especialmente do Nordeste. Isso não significa que eles tenham sucumbido a uma abordagem regionalista dos problemas tipicamente nordestinos, mas que através do esforço de recuperação da cultura e realidade nordestina buscavam mostrar o que havia de mais sincero sobre as condições e contradições no Brasil. Ou seria de se esperar de um Fabiano (personagem de Vidas Secas) ou um Paulo Honório (personagem de $S$. Bernardo) a possibilidade de negar-se a si mesmo, negar sua condição de classe, num pretenso "modo de agir regional".

A título de ilustração observemos a obra Vidas Secas de Graciliano Ramos (1970b), por exemplo, nela há uma passagem onde Fabiano de facão na mão, no meio do mato, se deparou com o Soldado Amarelo, o mesmo que havia sido responsável pela sua prisão e surra na cadeia, o que poderia fazer, o que ele fez? Afinal era "um sujeito violento, de coração perto da goela" (p. 146), como agir naquela fração de segundo? "Se houvesse durado mais tempo, o amarelo teria caído esperneando na poeira, com o quengo rachado" (p. 144). "O 
soldado, magrinho, enfezadinho, tremia "(p. 144); Fabiano "não quisera matar um cristão" (p. 144) "afastou-se, inquieto. Vendo-o acanalhado e ordeiro, o soldado ganhou coragem, avançou, pisou firme, perguntou o caminho [...] - Governo é governo [...] Tirou o chapéu de couro, curvou-se e ensinou o caminho ao soldado amarelo" (p. 152).

Neste capítulo, Graciliano Ramos fornece um perfeito exemplo da subalternidade e do conflito no personagem Fabiano, que poderia facilmente ter matado o Soldado Amarelo, não havia nenhum impedimento físico, afinal era cabra valente, estava armado e detestava profundamente aquele sujeito, então o que segurou sua mão naquela fração de segundo? Certamente não foi seu limitado "modo de agir regional". Nesse breve momento de uma fração de segundos, diversos elementos reais e ficcionais da realidade social do Nordeste explicam a contradição da hegemonia de uma particular articulação entre força e consenso que determinaram que governo é governo, e impediram Fabiano de desferir um golpe mortal no odioso soldado amarelo, que para além de si representava a estrutura social, representava o governo, ou o sistema de opressão e exploração ao qual estava submetido Fabiano, Sinhá Vitória, e os seus meninos sem nome.

Ainda seguindo nas ilustrações com Graciliano Ramos (1970b), destacamos em S. Bernardo o personagem Paulo Honório que se reinventa como capitalista, escapando a elevado custo do que seria o destino reservado a aqueles que nascem sem nada na vida além da sua capacidade de trabalhar. Paulo Honório se colocou acima de sua classe, e acredita que com isso estragou sua vida estupidamente. Depois da tragédia que marca sua vida, ele entende que nem sempre foi egoísta e brutal como aparece em grande parte da sua vida (do livro), foi a profissão - melhor dizendo, sua posição de classe - que lhe deu qualidades tão ruins. Através da visão de Paulo Honório encontramos o mundo sertanejo da grande propriedade, de grande exploração dos trabalhadores, de grande brutalidade e egoísmo, mas também de grande vazio e solidão.

Não se trata de uma produção voltada a explicar, criar, inventar, ou seja, lá o que for, o Nordeste, há uma universalidade nestas obras com grande riqueza estética e literárias, os destaques aqui aparecem com grande simplificação nesses comentários para fins puramente ilustrativos. Importa reter que essas obras expressam, mesmo quando limitadas pelas posições de classe dos intelectuais por trás delas, a realidade social do Nordeste.

Sobre a tese de Durval, e a crítica que estamos propondo, consideramos emblemático um parágrafo de Josué de Castro, em Sete Palmos de Terra e um Caixão, onde este diz que:

É ingênuo pensar que foi Julião quem inventou o problema agrário do Nordeste, que foi Arraes o autor da escravidão branca e das aspirações de justiça social, que foi Celso Furtado o revelador da economia dependente ou que fui eu [Josué de Castro] quem inventou a fome. Não inventamos nada. Todas essas coisas já tinham brotado naturalmente da estrutura social da região e crescido emocionalmente no seu clima humano de desespero e apenas aguardavam serem um dia revelados em termos mais ou menos racionais por alguns homens ou instituições da terra (CASTRO, 1967, p. 201). 
Josué de Castro, que mesmo sem demonstrar afinidade com o marxismo (nosso referencial teórico-metodológico) apresentou-se um materialista com grande destreza, dando uma excelente resposta a Durval Muniz e sua tese de invenção do nordeste, 30 anos antes desta ser lançada. "Não inventamos nada" disse ele, e concordamos integralmente, afinal a estrutura social da região marcada pelo problema agrário, pela dependência e pela fome é a base do que entendemos como questão nordestina. Esses elementos não são frutos da imaginação de Deus ou dos homens, não surgiram do discurso de representantes das classes abastadas, que mesmo que poderosas, não criam verbalmente, em busca de verbas, a seca, a fome e o abandono sem qualquer base material para tal. Como destacamos na introdução, não é a consciência que determina o ser, mas o ser social que determina consciência, o discurso ideológico não pode ser separado da realidade material, nem tampouco dissociar as formas de comunicação de sua base material.

Ainda pesa negativamente sobre a tese de "invenção do nordeste" a homogeneidade do espaço regional que transparece no livro. Ao pintar o Nordeste sendo concebido como uma região que está em toda parte e em lugar nenhum, ele não diferencia os espaços regionais, não considera que há Nordestes diferenciados pelas suas particularidades climáticas, econômicas e sociais.

A Gilberto Freyre é atribuída a invenção do Nordeste, mas este debruçou-se sobre o Nordeste do açúcar, de grandes barões montados em seus cavalos nos lamacentos terrenos de massapê, como aparece bem ilustrado na literatura de José Lins do Rego. O Nordeste do interior, da seca, do flagelo, da fome e das retiradas não aparece em Freyre, tampouco na sua construção de regionalidade. No sentido oposto, percebemos a diferença na forma de organização do espaço, através da diferenciação econômica e social que cada sub-região do Nordeste no processo de colonização e posteriormente no processo de modernização pós 1930.

Uma crítica materialista, em contraposição a essa abordagem pós-moderna, foi feita por Flávio Vieira (2001), que enfatiza que:

Ao desconsiderar o espaço como produção social, como materialidade, como conceito, e suas relações com as formações sociais distintas que foram gestadas como vários "nordestes" - o de José Lins do Rego, Rachel de Queiroz, Jorge Amado, Graciliano Ramos, só para citar alguns escritores com os quais Muniz trabalha - ele acaba por negar a importância de percebermos as especificidades históricas e sociais que ele diz tanto procurar (VIEIRA, 2001, p. 57).

É imprescindível considerar a realidade material, os aspectos que aparecem muito vivos e sofridos no discurso, como as secas, a violência, o descaso, etc., tem sua expressão na realidade nordestina. $O$ discurso ideológico sempre parte de alguma base material, nesse 
sentido os intelectuais "produtores dos discursos" que ele analisa não estão, nem poderiam estar desconectados das suas posições de classes.

O discurso regionalista é apresentado por Durval Muniz como sendo ideologicamente uma máscara da realidade. Em nossa concepção, amparados em Antonio Gramsci - no § 12 do caderno 11 - entendemos ideologia como "uma concepção de mundo, que se manifesta implicitamente na arte, no direito, na atividade econômica, em todas as manifestações de vida individuais e coletivas" (GRAMSCI, 2015, p. 98-99), nesse sentido a ideologia é social e historicamente produzida a partir da dinâmica social e econômica, ou seja, da relação e correlações de força entre as classes.

Em oposição a perspectiva de Durval Muniz, nossa leitura em relação ao movimento regionalista é que a intelectualidade tradicional freyreana ligada ao modo de produção anterior à "modernidade" capitalista buscava na defesa da tradição a preservação da classe dos grandes proprietários, expressando os interesses de classe.

Mas ao invés de criação da região de forma abstrata como propõe Durval Muniz, o resultado como destaca Manoel Correia de Andrade em análise da formação do pensamento regionalista é que o mesmo contribuiu para destruir a ideia de que o Brasil, esse imenso paíscontinente, compreendia apenas duas grandes Regiões: Norte e o Sul. Isso abriu espaço para uma melhor divisão das regiões brasileiras, que veio a acontecer através do Instituto Brasileiro de Geografia e Estatística (IBGE) criado na década de 1940 (ANDRADE, 2013).

E mesmo o Nordeste, Freyre não apresenta como único em sua totalidade, monolítico, mas como um conjunto. No que se refere aos pensadores da Segunda Geração Modernista, eles não estavam ligados aos interesses regionais, por mais que as obras fossem localizadas geograficamente, expressavam, ou buscavam expressar, as manifestações típicas da realidade brasileira (COUTINHO, 2013).

O movimento da segunda geração modernista não é homogêneo, nem poderia ser, e por isso pode-se perceber interpretações diversas acerca de uma mesma temática. E quando se diz perceber, é de fato perceber, considerando que se trata de uma produção literária romanesca (mesmo que profundamente realista), diferente da produção em tons sociológicos de Gilberto Freyre, que deixa explicita suas ideias e intenções.

\section{Considerações Finais}

O que fez Durval Muniz, em nosso entender, foi tentar produzir um discurso que propõe que o Nordeste foi inventado/gestado a partir de discursos, apartado de qualquer materialidade, sem avançar na busca dos elementos e contradições por trás dos mesmos, como se essas produções fossem um conjunto de estereótipos desgarrada dos intelectuais (e suas respectivas classes).

Por mais que o Movimento Regionalista em sua defesa da ideia de região buscasse manter os privilégios de uma classe tradicional, não significa que o discurso, por si só, tenha 
criado o espaço regional, mas sim que havia um interesse de classe, e que Gilberto Freyre foi esse porta-voz na condição de Intelectual tradicional da Casa-grande. Porta-voz de interesses localizados no tempo e no espaço.

Já a Geração de 30, com suas características de denúncia de maneira profundamente realista, faz o duplo movimento de apresentar o "verdadeiro" Brasil em toda sua precariedade, e luta pela sobrevivência; e, em outros casos, apresentar os auspício dos novos tempos com a necessidade de mudança daquela realidade, seja pela "modernização" capitalista que se anunciava, como em José Américo de Almeida, ou pela necessidade de superação das condições dadas com um viés socialista, como em Jorge Amado.

Além disso, percebe-se a ausência de importantes debates sobre a condição Nordestina, especialmente aqueles ligados à temática do desenvolvimento, que deveriam ser interlocutores privilegiados de Durval Muniz, mas ele os relega ao campo do "vitimismo". Deixando uma grande lacuna na sua tese, sem mencionar a homogeneidade do espaço regional, onde nem a divisão entre sertão e litoral aparece na sua construção desse nordeste inventado.

\section{Referências}

ALBUQUERQUE JR., Durval Muniz de. A Invenção do nordeste e outras artes. São Paulo: Cortez, 2011.

ALIAGA, Luciana. Gramsci e Pareto: Ciência, história e revolução. Curitiba: Apris, 2017.

ALMEIDA, José Américo de. A Bagaceira. Rio de Janeiro: Editora José Olympio, 1972.

ANDRADE, Manoel Correia de. Uma visão autêntica do Nordeste. In. FREYRE, Gilberto.

Nordeste: aspectos da influência da cana sobre a vida e a paisagem do Nordeste do Brasil [recurso eletrônico]. São Paulo: Global, 2013. Formato: ePub. Paginação irregular.

BAKHTIN, Mikhail. Marxismo e Filosofia da Linguagem: Problemas fundamentais do método sociológico da linguagem. São Paulo: Hucitec, 2014.

CASTRO, Josué de. Sete Palmos de Terra e um Caixão: Ensaios sobre o Nordeste uma área explosiva. São Paulo: Editora Brasiliense, 1967.

COUTINHO, Carlos Nelson. Cultura e Sociedade no Brasil: Ensaios sobre ideias e formas. São Paulo: Expressão Popular, 2011.

DANTAS, Cauby. Gilberto Freyre e José Lins do Rego: diálogos do senhor da casagrande com o menino de engenho [recurso eletrônico]. Campina Grande: EDUEPB, 2015. Formato: ePub. Paginação irregular

FREYRE, Gilberto. Manifesto regionalista. 7.ed. Recife: FUNDAJ, Ed. Massangana, 1996. p.47-75. 
FREYRE, Gilberto. Nordeste: aspectos da influência da cana sobre a vida e a paisagem do Nordeste do Brasil [recurso eletrônico]. São Paulo: Global, 2013. Formato: ePub. Paginação irregular

GRAMSCI, Antonio. Cadernos do Cárcere - Vol. 1: Introdução ao estudo de filosofia. A filosofia de Benedetto Croce. Rio de Janeiro: Civilização Brasileira, 2015.

IANNI, Octavio. O Ciclo da Revolução Burguesa. Petrópolis: Editora Vozes, 1985.

MARX, Karl; ENGELS, Friedrich. A ideologia alemã: crítica da mais recente filosofia alemã em seus representantes Feuerbach, B. Bauer e Stirner, e do socialismo alemão em seus diferentes profetas (1845-1846). São Paulo: Boitempo, 2007.

MARX, Karl. Introdução à Crítica da Economia Política [1857]. In. DANTAS, Gilson; TONELO, luri (org.). O Método em Karl Marx. São Paulo: Edições Iskra, 2016a p. 43-78

MARX, Karl. Prefácio de Marx ao livro Contribuição à Crítica da Economia Política [1959]. In. DANTAS, Gilson; TONELO, luri (org.). O Método em Karl Marx. São Paulo: Edições Iskra, 2016b. p. 37-42

RAGO, Margareth. O efeito-Foucault na historiografia brasileira. Tempo Social. $7(1-2)$, p. 6782, 1995.

RAMOS, Graciliano. O Romance do Nordeste. In. RAMOS, Graciliano. Garranchos: Textos Inéditos de Graciliano Ramos [recurso eletrônico]. Rio De Janeiro: Record, 2013. Formato: ePub. Paginação irregular

RAMOS, Graciliano. S. Bernardo. São Paulo: Martins, 1970a.

RAMOS, Graciliano. Vidas Secas. São Paulo: Martins, 1970b.

REGO, José Lins do. Menino de Engenho. Rio de Janeiro: José Olympio, 2010.

SANTOS, Nivalter Aires dos. Movimento Regionalista e Geração Literária de 30: Uma Análise Gramsciana. In. Encontro da Associação Nacional de Pós-graduação e Pesquisa em Ciências Sociais - ANPOCS, 40, 2016, Caxambu. Anais Eletrônicos... Caxambu, ANPOCS, 2016. VIEIRA, Flávio Lúcio R.. A Teia Inescapável do Regionalismo Nordestino: "A Invenção do Nordeste e outras artes”. Revista Conceito. João Pessoa, n. 5, p. 53-63. jun. 2001. 